\title{
The possibility of energy consumption reduction using the ECO driving mode based on the RDC test
}

The greenhouse effect and overall climate changes are the main reasons for developing ecological powertrain units dedicated to road vehicles. An electrical drivetrain without using conventional combustion engines fueled by hydrocarbon fuels is an effective method to significantly reduce $\mathrm{CO}_{2}$ emissions from the fleet. It is particularly vital in 2020 emission regulations aspects, and continuously the number of vehicles increasing. In this paper battery electric drive system of a small size passenger car was analyzed in terms of two different drive modes in cooperation with two recuperative braking modes. The research was carried out with real driving condition test requirements and driving parameters recording. Based on data obtained from OBD signals, energy flow and torque distribution have been specified. In results, overall reducing energy consumption has been achieved with ECO mode compared to normal mode. Selection of the driving mode ECO has a positive impact on reducing the state of charge saving more than 5\%, taking into account the whole RDC test; greater energy consumption reductions were observed in selected test areas.

Key words: electric vehicle, energy flow, regenerative braking, powertrain, driving mode

\section{Introduction}

The trends in the design of powertrains of road vehicles are mainly set by the changing exhaust emission legislation. It is a common knowledge that exhaust emissions have a negative impact on the natural environment and human health. Carbon dioxide, one of the main greenhouse gases (GHG) responsible for the global climatic changes, is generated, inter alia, during the combustion of hydrocarbonbased fuels in combustion engines (ICE) [28]. A significant contribution of road transport to the overall emission of GHG and the forecast of a $60 \%$ increase in the number of vehicles by 2035 compared to 2014 presented by International Organization of Motor Vehicle Manufacturers indicate the significance of the impact of this means of transport on the environment [2]. The effect is the tightening of the homologation regulations on the specific emission of $\mathrm{CO}_{2}$ from newly registered passenger vehicles and light duty trucks in the European Union. Starting from 2020, the admissible average emission of carbon dioxide from a fleet of vehicles is $95 \mathrm{~g} / \mathrm{km}$. The excess of this limit (past 2021) will be subject to an additional fee of 95 euros multiplied by the exceeded emission and the number of newly registered vehicles $[5,10]$.

An effective method of reduction of the $\mathrm{CO}_{2}$ emission from a fleet of vehicles is the application of zero-emission, particularly fuel-electric (EV) powertrains. The main group are the widely implemented battery electric vehicles (BEV) and, introduced by some of the carmakers, fuel-cell electric vehicles FCEV [38]. The experts forecast a reduction in the demand for diesel, gasoline and liquefied petroleum gas (LPG) fuels and an increased demand for electrical energy for the charging of $\mathrm{BEV}$ vehicles. The latter is to reach approx. 4806 GWh in 2035 in Poland, which gives a 178 times higher result compared to the 27 GWh in 2015 [19].

The current advancement of conventional powertrains allows the obtainment of an optimum point of work of a combustion engine by applying automatic transmissions. A proper application of the powertrain hybridization may have a positive impact on the shift of the engine operating range towards the area of lower fuel consumption. The application of an electric motor in the powertrain allows energy regeneration with a simultaneous process of high voltage battery charging, which allows the operation of the vehicle in a fully electric or hybrid mode. In order to systematize the structures of cooperation of an electric motor in vehicle powertrains, designations from P0 to P4 were adopted (Fig. 1). For example P0 identifies belt-driven MGs attached to the front of the engine. A P2 with the PHEV capability actually delivers better overall efficiency in pure electric mode than the powersplit type. P4 allows the fitting of the electric motor directly in the driven axle.

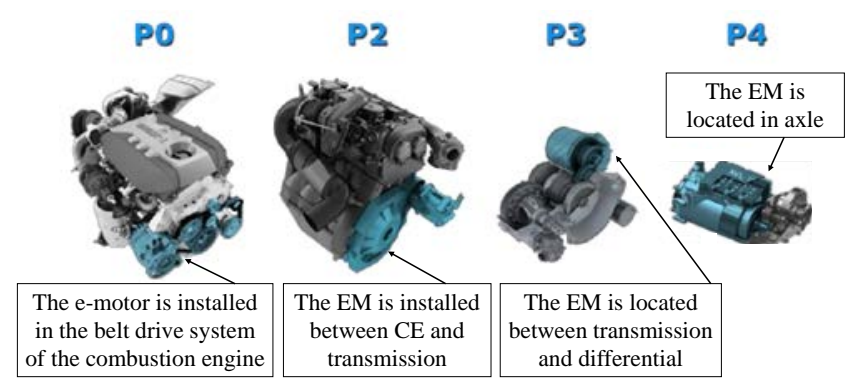

Fig. 1. Electrification of ICE-based powertrain systems [15]

In the years 2010-2019 a significant increase in the worldwide sales of electric vehicles was recorded (Fig. 2). The greatest number of electric vehicles is sold in China. The sales in the US and Europe are also significant. The number of BEV vehicles registered in Poland increased over two times from 895 in 2018 to 1677 in 2019 [26]. In multiple publications, [11, 26, 32] a further intense fleet electrification is forecasted. 


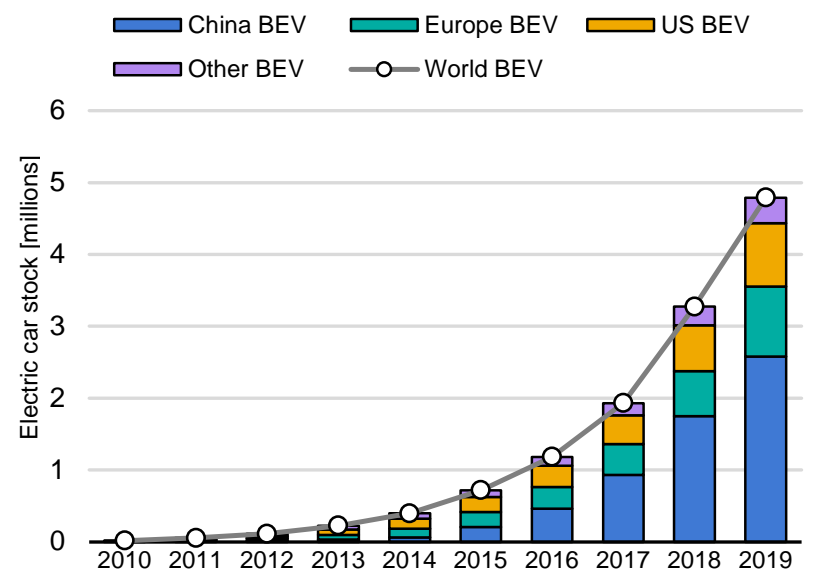

Fig. 2. World sales of Battery Electric Vehicle between 2010-2019 [27]

When considering the influence of a BEV vehicle on the environment, attention should be drawn to the source of electrical energy, which has a direct impact on the emission of carbon dioxide [37]. Burchart-Karol et al. [4] have evaluated the influence of battery charging on the natural environment going on the assumption of a constant energy consumption of $19.9 \mathrm{kWh} / 100 \mathrm{~km}$ by a vehicle in different EU member states. The criteria of evaluation were the emission of greenhouse gases, human health, water consumption, impact on the eco-system and depletion of natural resources. In the majority of the analyzed countries, the influence of electric vehicle charging decreased in subsequent years along with the increase in the share of renewable energy used for the charging. The battery charging had the smallest environmental impact in France, taking into account the majority of the analyzed categories, while in the case of Denmark the smallest cumulative water use was observed. The most environment-friendly source of renewable energy for the BEV vehicles was the wind energy. The performed comparative Life Cycle Assessment (LCA) for the BEV vehicles and a conventional ICEV with particular focus on utilization indicate a greater environmental impact of BEV vehicles at the stage of production. This is particularly caused by the process of production of batteries and other materials [21, 34]. An important problem in the advancement of BEV electric vehicles is the effective and ecological method of storage of electrical energy. Today, the most common material for the production of batteries is lithium, and the manufacturers estimate the life of such batteries at 6-8 years. When the battery capacity decreases by $20-30 \%$, it is to be renewed [8, 36]. This type of batteries can be rebuilt [83], used again for other purposes such as energy storage from renewable sources [6] or recycled [7]. Given the cost of battery production reaching 35\% of the final price of the vehicle, the fact of its further life is significant [36] and the assessment of the aging process is a subject of research $[3,30]$. The application of batteries of lower capacity in vehicles without a significant reduction of the vehicle range is possible by the application of light materials such as aluminum and carbon fiber reinforced plastic for their production [31].

The range of a BEV vehicle depends on the battery capacity, energy consumption by the vehicle and the automo- tive comfort systems. An efficient method of energy saving and at the same time an unparalleled advantage of electric vehicles is the possibility of energy regeneration from braking. The energy lost during braking is estimated at $50 \%$ of the energy used for the operation of the vehicle, particularly under the conditions of urban driving [20]. An important factor is also the driving style. Questionnaire-based research carried out among drivers of conventional vehicles (ICE) and EV [40] has shown a greater tendency of drivers to apply eco-driving when using an electric vehicle. This is exhibited by smoother driving with limited braking and limited hard acceleration. Such drivers are also more likely to extend the time of traveling to ensure lower energy consumption. The in-vehicle display (IVD) technologies appear quite helpful in maintaining the proper driving style.

Due to the limited range of BEV vehicles, hence the need to plan the trip, forecasting energy consumption and identification of the factors influencing this consumption is extremely important from the user's point of view. Zhichen et al. [38] used a simulation to compare the efficiency of energy recovery from a BEV vehicle. Three test routes of different average speeds were selected for comparison. The greatest amount of energy was recovered for the slowest test route (33.4\%) and the smallest amount was recovered for the fastest (expressway) route. More simulations were carried out by Gao et al. [16]. They compared the influence of eco-driving for three different types of vehicles used according to their intended use. Eco-driving style was based on the reduction of frictional braking loss via appropriate speed control, avoiding unnecessary braking and, if possible, shortening the standstill time. The benefits of ecodriving using full electric powertrain reduce the energy consumption in passenger vehicles by $27 \%$, buses $22 \%$ and heavy-duty trucks by $8 \%$ (Fig. 3). For conventional powertrains the impact of eco-driving is even greater. In the said paper, the authors also presented the significance of loss during regenerative braking. They indicate a possibly great reduction of braking in order to limit the loss.

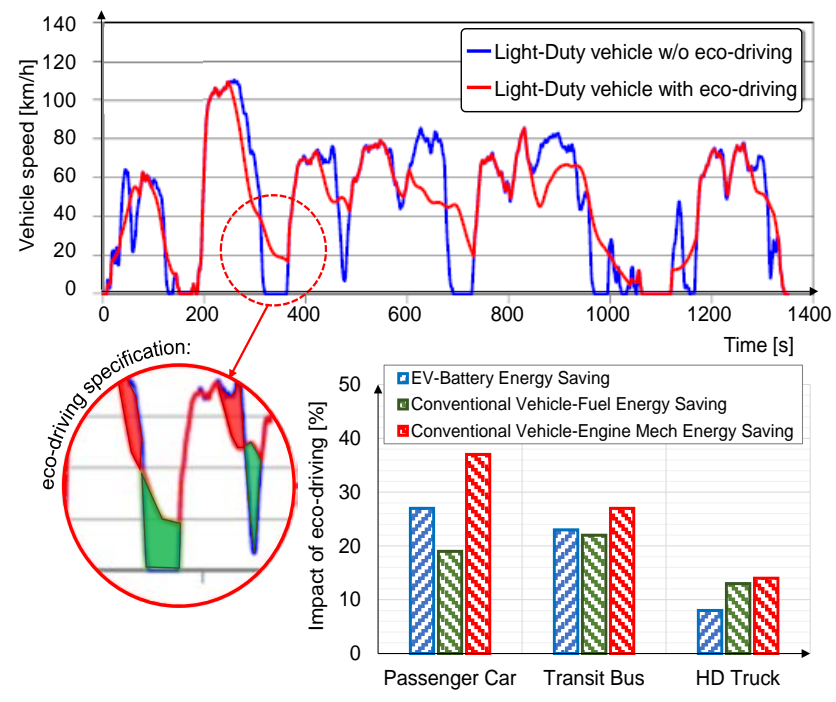

Fig. 3. Example of passenger car speed profiles with and without ecodriving applied and a comparison of the percent energy savings of the EVs and conventional vehicles resulting from eco-driving [16] 
Another energy consumption test was performed on a $90 \mathrm{~kW}$ electric vehicle under real traffic conditions in compliance with the RDE test requirements [17]. As a result of two correctly realized test runs, an average energy consumption of $19.6 \mathrm{kWh}$ was obtained. In road tests, it is important to identify the factors influencing the energy consumption (the consumption of energy by additional equipment and braking strategy). With the assistance of the developed model [1], the authors have proven a $15-40 \%$ increase in the overall energy consumption by a vehicle driven at the speed of $20 \mathrm{~km} / \mathrm{h}$ and $5-15 \%$ for the average speed of $60 \mathrm{~km} / \mathrm{h}$ assuming additional energy consumption on the level of 250-750 W. Additional energy consumption denotes energy consumed by climate control, interior lighting, multimedia and vehicle control. The analysis of the amount of energy recovered during braking indicates a reduction in the energy recovery along with the increasing average speed of the test run. Another aspect influencing the energy consumption is the traffic management strategy that changes the speed profiles of the vehicle [13]. The probabilistic approach analyzing four different infrastructure scenarios indicates varied energy consumption and proposes the application of the developed model in further works. Kalt et al. [29] have attempted to develop a representative driving cycle dedicated for use when designing electric powertrains. Data from a large number of EV taxicabs and personal vehicles were recorded with the resolution of $1 \mathrm{~Hz}$. The results indicate greater acceleration values and higher average speeds than those specified by the WLTP test. It has also been confirmed that a single test cannot reflect all the cases of actual traffic operation and work points of the powertrain. When calculating the energy consumption, one must allow for the type of road. Tests performed on a chassis dynamometer according to the NEDC test requirements indicate a great significance of the arterial road [12]. Forecasting of energy consumption can be done using two paths - the offline mode based on the information pulled from vehicle systems supplemented with the information obtained in the online mode. The performed comparison of the forecast with the actual traffic conditions have rendered positive results - the difference in the energy consumption did not exceed $10 \%$ [41].

In the analyzed literature, authors draw attention to the energy consumption of a BEV vehicle directly related to its range. Predicting energy consumption based on the assessment of the vehicle energy consumption is a key factor in the further advancement of electric vehicle technology. A proper assessment should be made under actual traffic conditions, as the tests do not entirely reflect the driving dynamics. The influence of the driving dynamics on the final results is critical. In the paper, the authors attempted to analyze the energy consumption of a passenger vehicle from the A category BEV vehicle allowing for regenerative braking strategies and the available driving modes implemented by the manufacturer based on road tests performed in compliance with the RDC procedure. Similar works have been performed earlier on vehicles fitted with a hybrid drive (combustion engine-electric) [9, 14, 35].

\section{Aim of the research}

The aim of the performed research was the evaluation of the energy consumption of a Skoda CITIGO ${ }^{\mathrm{i}}$ iV battery electric vehicle allowing for the actual traffic conditions and the use of different powertrain modes. The following research questions were posed: How much energy does a city electric vehicle consume during its intended operation? What economies can be expected by varying the operation of the powertrain (restricting the instantaneous power output and maximum speed of the vehicle)? The scope of the research included two test runs compliant with the RDC test procedure in urban, rural and motorway cycles. The control of the powertrain included modifying the regenerative braking strategy and activation of the eco-mode (limited energy consumption). The data from the test run were recorded in real time based on the information pulled from the vehicle CAN network by a dedicated OBD diagnostic scan tool.

The assessment of the energy flow was made in compliance with the RDC driving cycles, also used in the RDE tests. To this end, research procedure compliance analyses were performed $[18,33]$. The flow of the energy $\Delta \mathrm{E}$ was determined based on the flow of current and voltage of the battery as a result of its discharge, charge and regenerative braking:

$$
\Delta \mathrm{E}_{\mathrm{i}}=\sum_{\mathrm{t}=0}^{\mathrm{t}=\mathrm{t}_{\text {max }}} \mathrm{U}_{\mathrm{BAT}} \cdot \mathrm{I}_{\mathrm{BAT}} \mathrm{dt}
$$

- discharging:

$$
\Delta \mathrm{E}_{\text {dis }}=\sum_{\mathrm{t}=0}^{\mathrm{t}=\mathrm{t}_{\text {max }}} \mathrm{U}_{\mathrm{BAT}} \cdot \mathrm{I}_{\mathrm{BAT}} \mathrm{dt}\left(\text { when } \Delta \mathrm{E}_{\mathrm{i}}<0\right)
$$

- charging:

$$
\begin{aligned}
& \Delta \mathrm{E}_{\text {ch }}=\sum_{\mathrm{t}=0}^{\mathrm{t}=\mathrm{t}_{\text {max }}} \mathrm{U}_{\mathrm{BAT}} \cdot \mathrm{I}_{\mathrm{BAT}} \mathrm{dt} \\
& \left(\text { when } \Delta \mathrm{E}_{\mathrm{i}}>0 \text { and } \mathrm{M}_{\text {reg }} \geq 0\right)
\end{aligned}
$$

- $\quad$ energy recovery (regenerative braking):

$$
\begin{gathered}
\Delta \mathrm{E}_{\text {reg }}=\sum_{\mathrm{t}=0}^{\mathrm{t}=\mathrm{t}_{\max }} \mathrm{U}_{\mathrm{BAT}} \cdot \mathrm{I}_{\mathrm{BAT}} \mathrm{dt} \\
\left(\text { when } \Delta \mathrm{E}_{\mathrm{i}}>0 \text { and } \mathrm{M}_{\text {reg }}<0\right. \text { ) }
\end{gathered}
$$

where: $\mathrm{U}_{\mathrm{BAT}}$ - voltage [V], $\mathrm{I}_{\mathrm{BAT}}$ - current [A], dt - time [h], $\mathrm{M}_{\text {reg }}$ - braking torque [Nm].

In order to determine the individual electric powertrain operating conditions, road portions were specified where the system operated in these individual conditions. On this basis, the operating modes were divided into individual phases: driving, acceleration, standstill and braking during operation of the electric drive. The adopted criteria have been shown in Table 1.

Table 1 . Vehicle motion phase criteria

\begin{tabular}{|l|l|}
\hline \multicolumn{1}{|c|}{ Mode } & \multicolumn{1}{c|}{ Parameters } \\
\hline EV mode & $\mathrm{a}=0, \mathrm{v}>0$ \\
\hline Acceleration EV & $\mathrm{a}>0, \mathrm{v}>0$ \\
\hline Standstill & $\mathrm{v}=0$ \\
\hline EV regenerative braking & $\mathrm{a}<0, \mathrm{v}>0, \mathrm{I}_{\mathrm{BAT}}>0$ \\
\hline
\end{tabular}




\section{Research object}

The investigations were carried out using a vehicle fitted with a ŠKODA CITIGO ${ }^{\mathrm{i}} \mathrm{iV}$ electric drive allowing different driving modes and variable intensity of regenerative braking. The ŠKODA CITIGO ${ }^{\mathrm{i}} \mathrm{iV}$ powertrain of the power output of $61 \mathrm{~kW}$ used a Li-Ion battery of the full capacity of $36.8 \mathrm{kWh}$ and useable capacity $32.3 \mathrm{kWh}$. The location of the batteries has been presented in Fig. 4. The batteries are fitted in the tunnel between the seats, under the driver and passenger's seats and under the rear seats. The parameters of the investigated vehicle have been presented in Table 2.

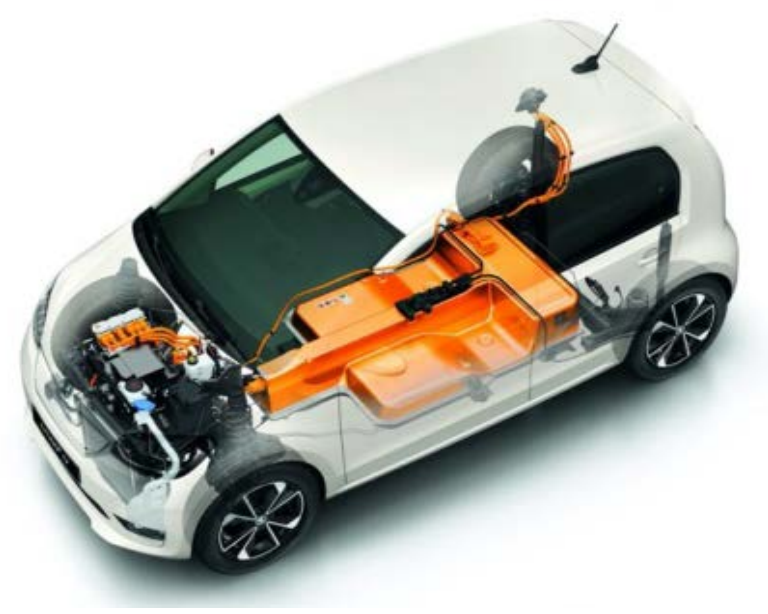

Fig. 4. Location of the battery in the vehicle [24]

Table 2. Technical data of the analyzed powertrain fitted in Skoda CITIGO $^{\mathrm{i}} \mathrm{iV}$ [39]

\begin{tabular}{|l|c|}
\hline \multicolumn{2}{|c|}{ Electric motor } \\
\hline \multicolumn{2}{|c|}{ ŠKODA CITIGO ${ }^{\mathrm{i}} \mathrm{iV}$} \\
\hline Max. voltage [V] & 360 \\
\hline Max. power output [kW/KM] & $61(82)$ \\
\hline Max. torque [Nm] Battery \\
\hline \multicolumn{2}{|c|}{} \\
\hline Type & Li-Ion \\
\hline Capacity [kWh] & 32.3 \\
\hline
\end{tabular}

The analyzed electric vehicle is a redesigned version of the original model fitted with a conventional combustion engine powertrain. In the original powertrain, the engineers fitted a naturally aspirated 1.0L three-cylinder indirect fuel injected (MPI) gasoline engine (Fig. 5) combined with a 5 speed automatic transmission. The electric version of CITIGO $^{\mathrm{i}} \mathrm{iV}$ is fitted with a liquid-cooled three-phase powertrain (Fig. 6) with a single electric motor of a constant gear ratio.

Figure 7 presents the performance of two types of powertrains used in the analyzed vehicle model. The electric $61 \mathrm{~kW}$ motor marked red and the most powerful version of the combustion engine (55 kW) are used in this car model. The main difference between the engine and the electric motor is the speed range resulting from the design differences. It is noteworthy that the comparison involved the engines only, not the entire powertrain. The powertrains differ in the way the power is transferred to the wheels. In the case of the electric motor, a constant ratio transmission was applied while the conventional powertrain included a multi-speed manual or automatic transmission.

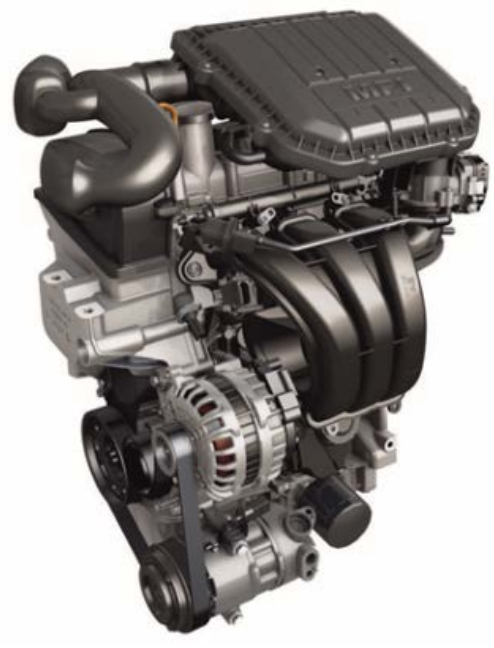

Fig. 5. The gasoline engine used in the conventional Skoda CITIGO ${ }^{\mathrm{i}} \mathrm{V}$ powertrain system [25]

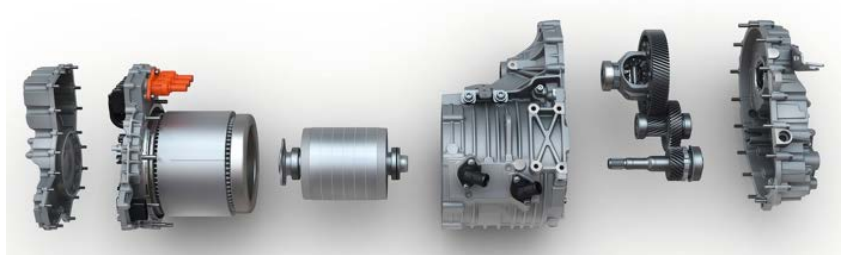

Fig. 6. Design of the Skoda Citigo ${ }^{\mathrm{i}}$ iV electric powertrain unit [23]

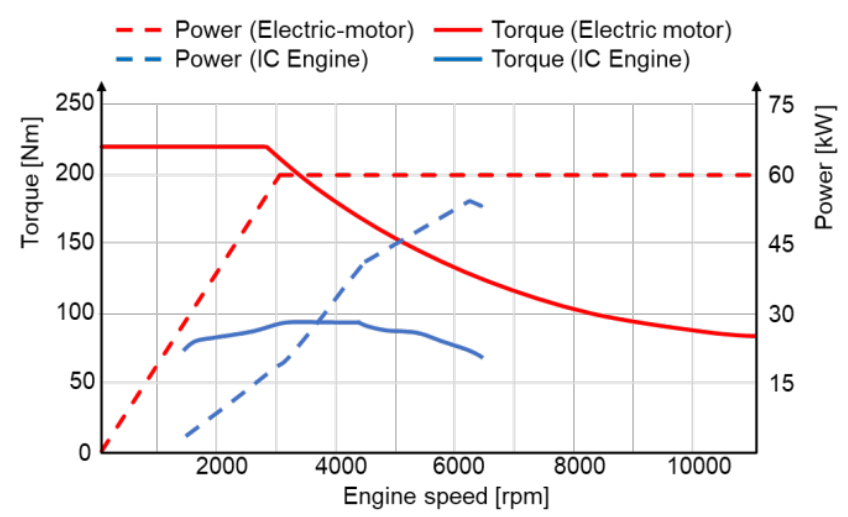

Fig. 7. Catalogue comparison of the performance of the electric motor and the internal combustion engine fitted in Skoda CITIGO ${ }^{\mathrm{e}}$ iV [39]

\section{Research methodology}

The investigations presented in this paper were performed experimentally based on the test runs carried out on a BEV vehicle on the predetermined route in compliance with the RDE homologation tests. The advantage of the said tests is that the cycles are defined so as to represent a real life scenario. They must take into account variable environment, road slopes, wind, traffic and different driving behaviors (Fig. 8). As per the presented range, the RDE test provides the analysis of the powertrain in its widest possible range of operation. 


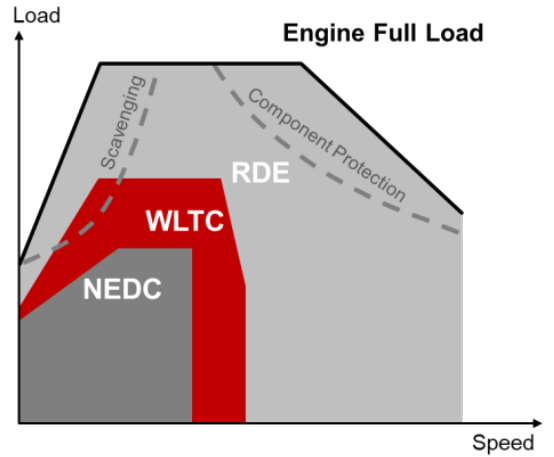

Fig. 8. Emission norm cycle operating ranges comparisons [22]

The selected route (Fig. 9) went through the city of Poznań and its surrounding areas. It covered urban, rural and motorway portions. The maximum legal speed on the latter is $140 \mathrm{~km} / \mathrm{h}$. The test route was proposed and determined following another paper by the authors [14] and its determination was not the purpose of this paper. Selected test requirements related to the course of the test run have been presented in Table 3. As per the requirements, the duration of all the test runs exceeded 90 minutes.

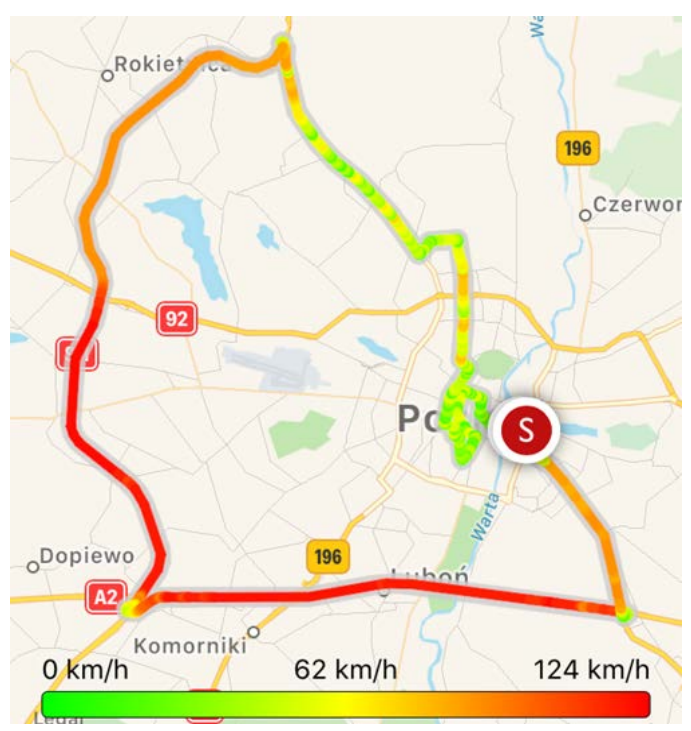

Fig. 9. Route pattern followed in the research

Table 3. Real Driving Conditions test requirements

\begin{tabular}{|l|c|c|c|}
\hline $\begin{array}{l}\text { Selected RDE/RDC test } \\
\text { requirements }\end{array}$ & Urban & Rural & Motorway \\
\hline $\begin{array}{l}\text { Cycle repetition } \\
( \pm 10 \%)[\%]\end{array}$ & $29<$ ratio $\leq 34$ & 33 & $\leftarrow$ \\
\hline Speed [km/h] & -60 & $\begin{array}{c}60 \leq \mathrm{V} \\
\leq 90\end{array}$ & $\mathrm{~V}>90$ \\
\hline $\begin{array}{l}\text { Max. speed ( } \pm 15 \mathrm{~km} / \mathrm{h} \\
\text { for less than 3\% } \\
\text { of driving time) [km/h] }\end{array}$ & $15 \leq \mathrm{V} \leq 30$ & - & 145 \\
\hline $\begin{array}{l}\text { Average speed (stops } \\
\text { included) [km/h] }\end{array}$ & 16 & $\leftarrow$ & $\leftarrow$ \\
\hline $\begin{array}{l}\text { Minimum travelled } \\
\text { distance [km] }\end{array}$ & 100 & $\leftarrow$ & $\leftarrow$ \\
\hline $\begin{array}{l}\text { Altitude difference } \\
\text { (beginning/end) [m] }\end{array}$ & $1200 \mathrm{~m} / 100 \mathrm{~km}$ & $\leftarrow$ & $\leftarrow$ \\
\hline $\begin{array}{l}\text { Maximum slope } \\
\text { [m/100 km] }\end{array}$ & & & $\leftarrow$ \\
\hline
\end{tabular}

Two runs were carried out at the same time of day, day after day in order to ensure possibly reproducible test conditions. The average ambient temperature was $22^{\circ} \mathrm{C}$ and ambient pressure $1015 \mathrm{hPa}$.

In the analyzed passenger car, four recuperation braking intensity levels from 1 to 4 are available (Fig. 10). Level 1 means the lowest braking intensity, Level 4, also called "B" means the biggest intensity. The electric motor automatically realizes the braking while releasing the accelerator pedal.
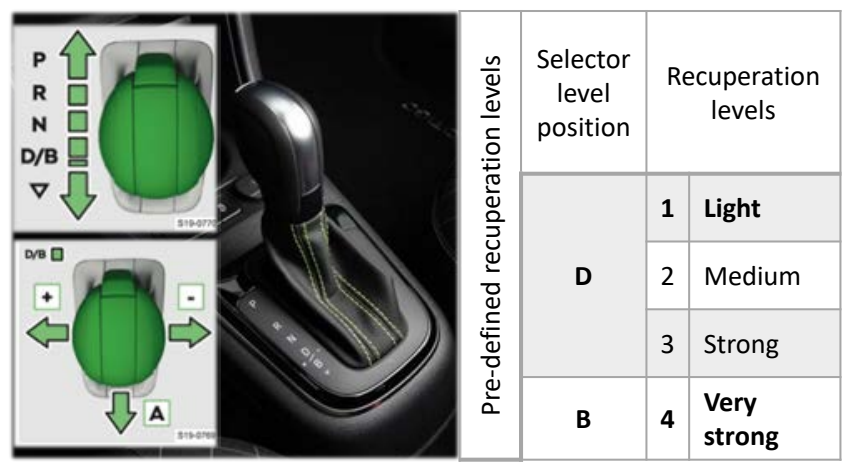

Fig. 10. Available recuperation levels (results of tests for D1 and B4 modes presented in this article) [39]

During the first test run, the vehicle operated in the NORMAL mode, which means all energy saving systems were deactivated. Additionally, the regenerative braking assistance was set to minimum (level 1). Automatic braking was minimum and the vehicle was in the sailing mode. In the consecutive test run, the ECO mode was activated with a button located in the central console (Fig. 11). In this mode, the maximum vehicle speed was restricted to 120 $\mathrm{km} / \mathrm{h}$ and the maximum power output to $80 \%$. In extreme unexpected road situations it is possible to obtain the maximum power by depressing the accelerator pedal to the floor. Additionally to the activation of the ECO system, regenerative braking was set to level B (level 4). In this mode, the vehicle automatically braked with the energy regeneration function using the electric motor as the driver retracts the foot from the accelerator pedal.

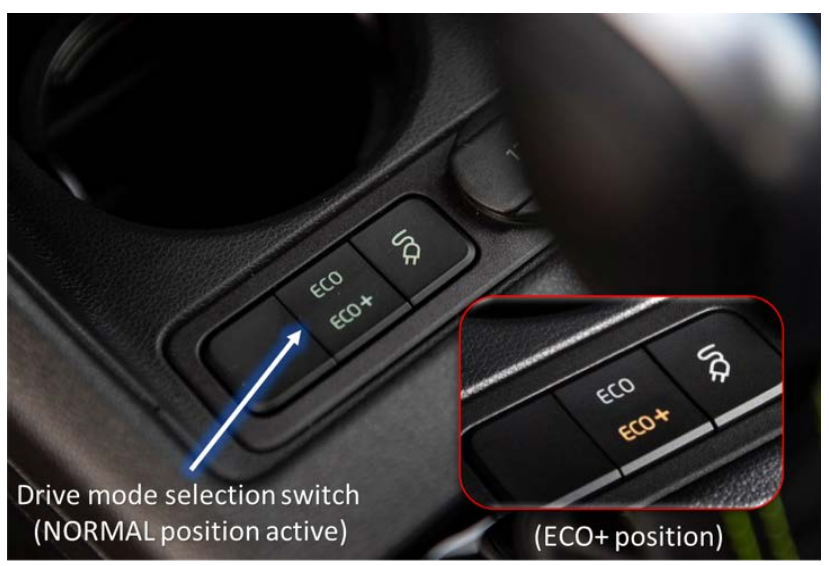

Fig. 11. The location of the ECO mode button [39]

Given the fact that the analyzed vehicle was fitted with an electric drive, precise data related to the operation of the powertrain were pulled in real time from the CAN network 
through a diagnostic scan tool. Nine parameters were recorded that were used for further analysis. The course of the test route was recorded with a mobile GPS device. The view of the equipment and its arrangement has been shown in Fig. 12.

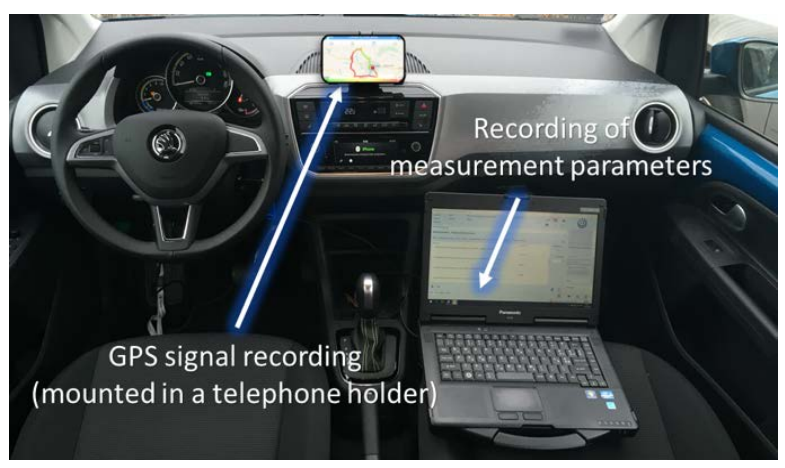

Fig. 12. Arrangement of the data acquisition equipment during the tests

\section{Results and discussions}

The driving cycles realized in compliance with the RDC procedures were started at the battery level SOC 100\% (software readout). The test runs were performed by a single driver to avoid inconsistency in the driving style. During the test run, the vehicle speed and battery level were recorded. The results have been presented in Fig. 13.

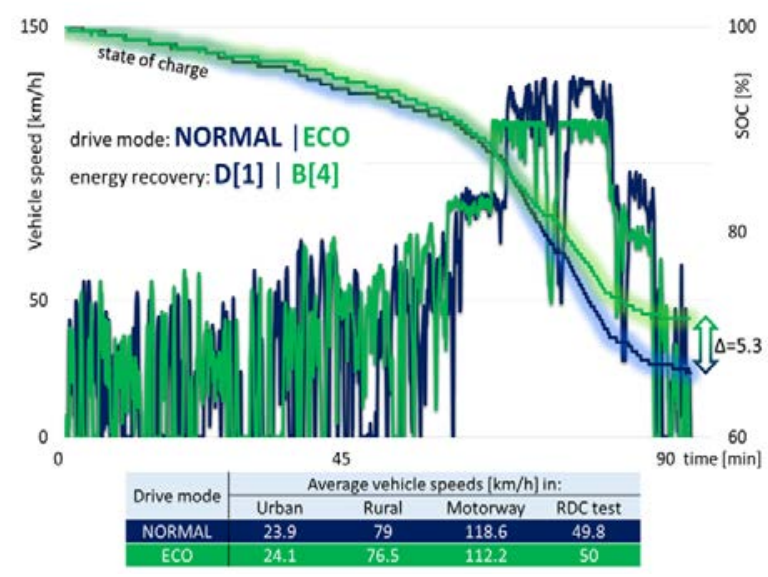

Fig. 13. Comparison of the RDC test for the performed test runs in the NORMAL and ECO modes

The tracing shows the speed profile and current SOC as a function of time. Additionally, in the table, the authors presented the average speeds in the analyzed speed intervals as divided into road portions. The beginning of the test route was the urban cycle where the vehicle speed did not exceed $60 \mathrm{~km} / \mathrm{h}$. The next one was the rural area with the speeds of $60-90 \mathrm{~km} / \mathrm{h}$ and the motorway with the speed in excess of $90 \mathrm{~km} / \mathrm{h}$. The SOC decreased in time with the intensity depending on the vehicle speed. During the realization of the first part of the test, no significant difference was recorded between the NORMAL and ECO modes in the urban cycle, which results from the similar average speeds in the urban area. An increase in the average speed in the rural portion resulted in an increase in the energy consumption in the NORMAL mode. The greatest differences were observed when the vehicle operated at the high- est speed during the test. The difference in the average speeds in this road portion was $6.5 \mathrm{~km} / \mathrm{h}$. This results from the speed restriction to $120 \mathrm{~km} / \mathrm{h}$ in the ECO mode. The change in the driving mode to ECO resulted in a decrease in the battery discharge level by 5.3\%. This indicates the significance of the vehicle speed on the energy consumption, particularly at high speeds. This is influenced by the vehicle motion resistance. Despite the differences in the average speeds in the analyzed portions, the final values of the average speeds for the entire tests are similar, which gives grounds for further reliable analysis.

A selective analysis of the test results allowed determining of the share of individual drive phases against distance and time (Fig. 14). A drive phase with a constant speed was distinguished when the vehicle acceleration equaled $\mathrm{a}=0$, change of speed where the acceleration/deceleration assumed values +/- and stoppage where the vehicle speed equaled $\mathrm{V}=0 \mathrm{~km} / \mathrm{h}$. For both powertrain modes, the greatest share had the phase with the constant speed, which is particularly visible when we consider it in relation to the covered distance. The drive in the ECO mode was characterized with a smaller share of acceleration and deceleration and a greater share of driving with a constant speed. The process of energy recovery from braking and acceleration leads to loss generated during the conversion of electrical energy into mechanical one and vice versa. Limiting these phases leads to a reduction of the energy conversion loss, which reduces the energy consumption by the vehicle.
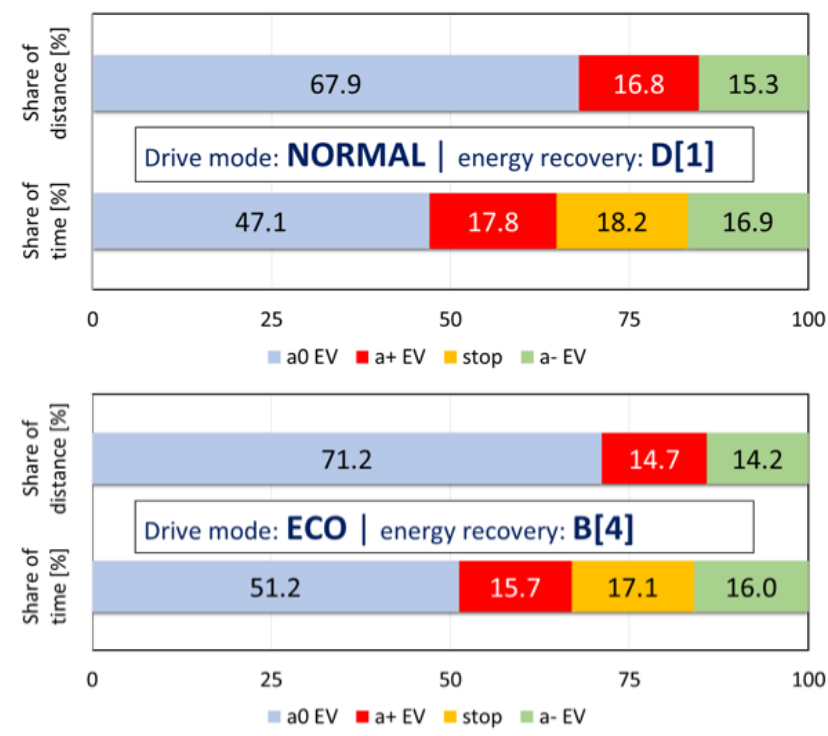

Fig. 14. Comparison of the phase motion share during the RDC test with NORMAL and ECO modes

The share of individual drive phases in time has been presented in detail in Fig. 15. When comparing both test runs, we can see differences in the distribution of the individual phases. This is related to the dynamically changing traffic conditions. In the case of road tests, these types of differences among the test runs are unavoidable and extremely valuable when further analyzed, particularly when developing energy consumption models. 

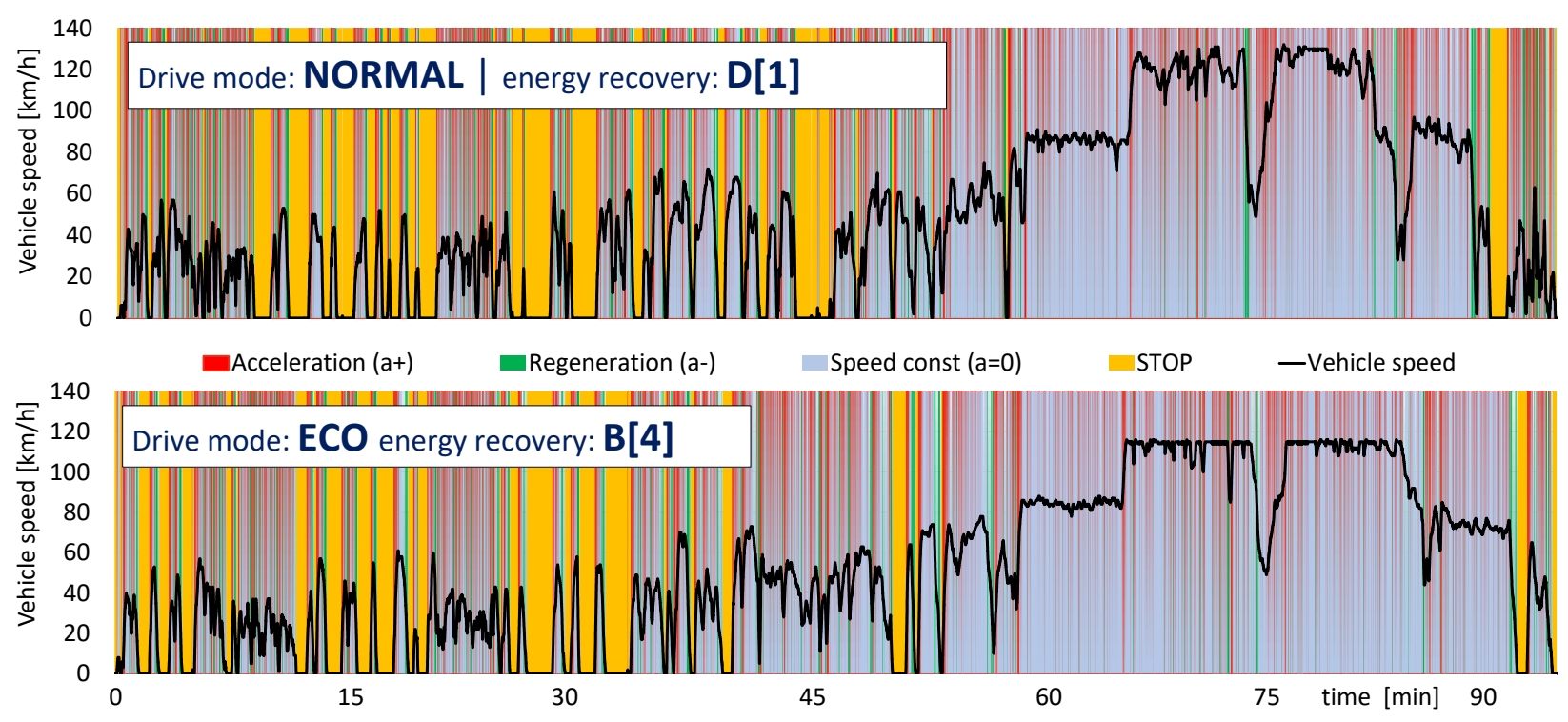

Fig. 15. Distribution of motion phases in terms of NORMAL and ECO driving modes

In EV vehicles, the flow of energy between the source and the electric machine is an extremely important aspect. In this paper, it has been determined based on the voltage and the current flowing to the motor during acceleration and from the electric motor to the battery during regenerative braking.

Figure 16 presents the flows of energy for both realized driving modes. The bar chart pertains to the collective share of a given vehicle speed in the entire test for a given speed interval against distance and time.
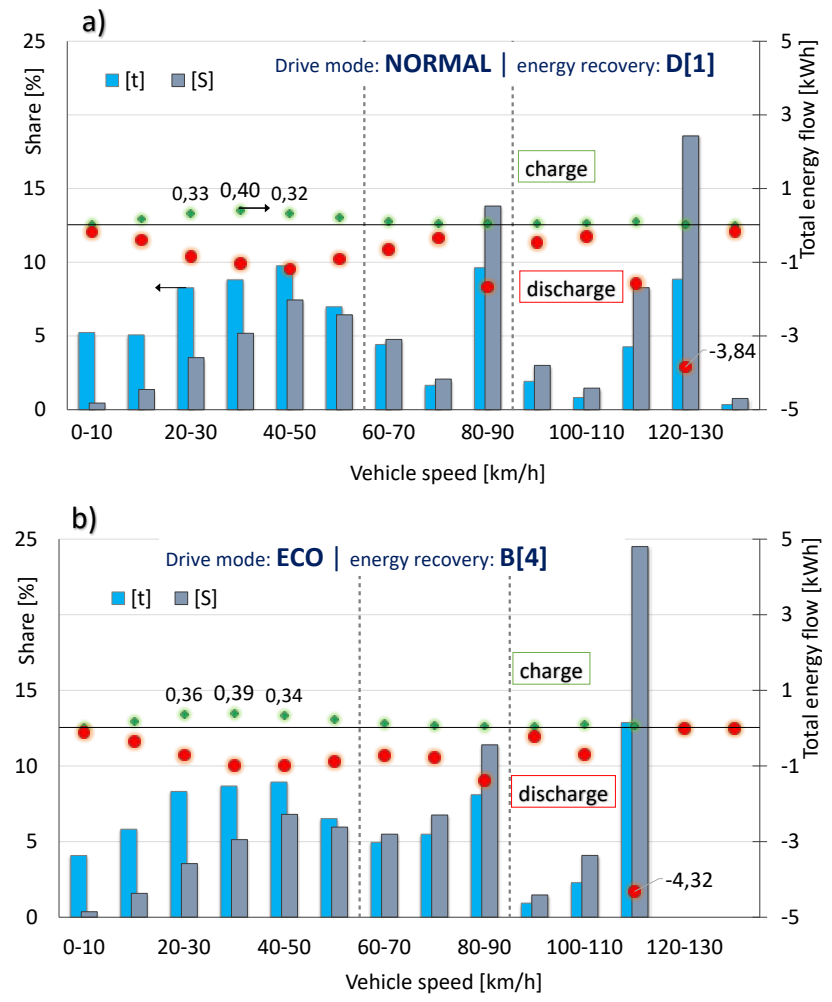

Fig. 16. Energy flow characteristic and the share of energy consumption for different speed intervals in the RDC tests; a) NORMAL D[1]; b) ECO B[4]
The marked points present the total flow of the recovered (green) and consumed (red) energy in a given speed interval. For both test runs (a, b), the same nature of changes of the energy flow was recorded. Small differences were found in values in individual speed intervals. Due to the speed restriction in the ECO mode, the greatest share in the energy consumption was observed for the speed interval of $110-120 \mathrm{~km} / \mathrm{h}$. The greatest amount of energy was recovered in the speed interval of $20-40 \mathrm{~km} / \mathrm{h}$. The amount of recovered energy in the urban speeds interval allows extending the vehicle range. However, the energy consumption in each speed interval is higher.

In Figure 17 collective values of the energy flow for each speed interval (bar chart) have been compared with the values of instantaneous energy flow (point chart). The sampling frequency of the diagnostic system was approx. $4 \mathrm{~Hz}$, hence the presented results of the instantaneous maximum energy flow pertain to the energy recovery or consumption in the time of $0.25 \mathrm{~s}$. In the NORMAL mode (a), which was the case when the vehicle operated at the speed exceeding $120 \mathrm{~km} / \mathrm{h}$, a maximum energy consumption greater by 1.74 $\mathrm{kWh}$ was obtained for the $120-130 \mathrm{~km} / \mathrm{h}$ interval against the maximum total energy consumption obtained in the ECO mode (b) in the $110-120 \mathrm{~km} / \mathrm{h}$ interval. In the NORMAL mode of the smallest assistance in regenerative braking, the instantaneous values of recovered energy were on a constant level between 40 and $120 \mathrm{~km} / \mathrm{h}$. In the case of the ECO mode, the activation of the regenerative braking assistance $B(4)$, in the speed interval $80-0 \mathrm{~km} / \mathrm{h}$ resulted in a lower maximum value of recovered energy. The difference may have resulted from the irregularity of the regenerative braking process. When the regenerative braking assistance is off, the driver uses the brake in the same way during each braking. If mode $B$ is used, the vehicle mostly brakes automatically when the driver takes the foot off the gas pedal and the brake is used only in emergency situations or when the vehicle is decelerated from high speeds. It is these situations that decide about the reduction of the energy recovered during braking. 

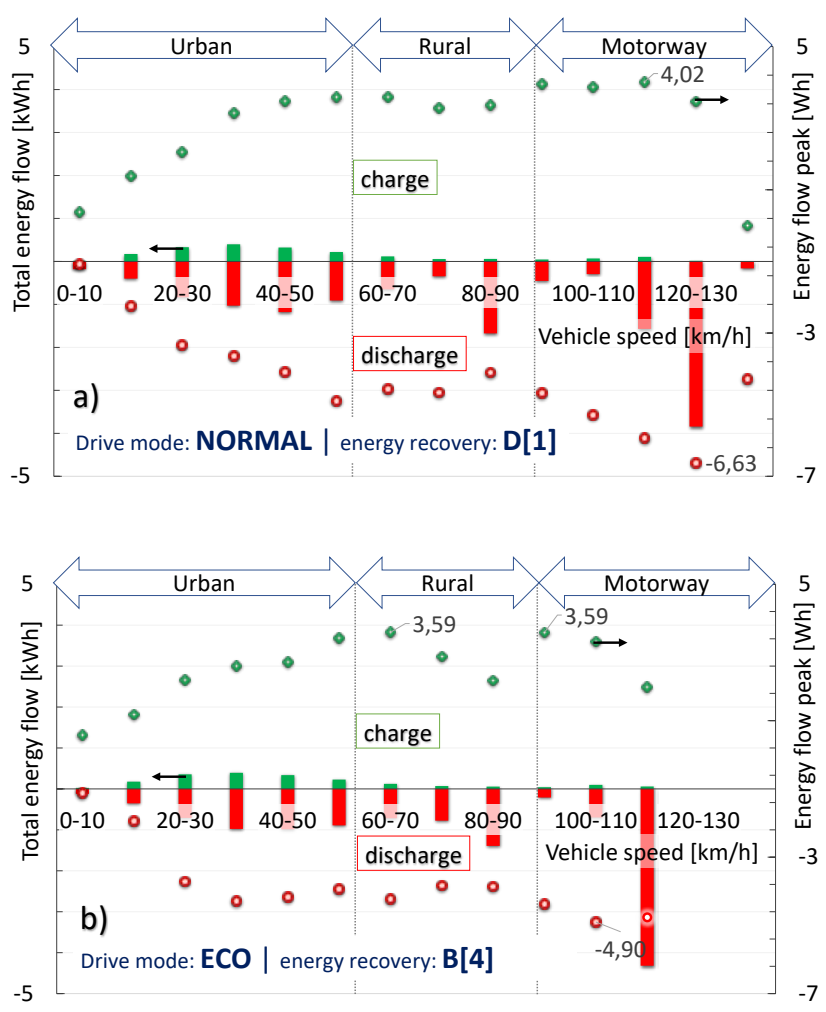

Fig. 17. Total energy flow characteristics and peak values for different speed intervals in the RDC tests; a) NORMAL D[1]; b) ECO B[4]

The energy balance allowing for the type of the test road portion has been presented in Fig. 18. Irrespective of the applied driving and braking mode, the same values of recovered energy were obtained during braking in each road portion. The greatest amount of energy was recovered in the urban cycle due to the high number of breakings compared to the road portions where the traffic was smooth. The activation of the ECO mode allowed a reduction of the energy consumption by $13 \%$ in the urban cycle and $18 \%$ in the expressway cycle. An increased consumption was recorded in the rural cycle. The above, however, may have resulted from the variable traffic conditions in the RDC test. The differences may have been caused by the restricted power output when the vehicle accelerated.

A great advantage of the electric drive is the ability to generate high torque at a relatively low speed of the motor. The last stage of the research presented in the paper was the identification of the torque distribution during the road tests. Figure 19 presents the distribution of the value of torque generated for the engine speed against the experimentally created full load characteristics in a given vehicle driving mode. The chart shows the restrictions applied when activating the ECO mode (torque reduction) and the initial fluctuations attributed to the activation of the restrictions. It is noteworthy that, in the case of the analyzed vehicle, the engine speed was directly proportional to the vehicle speed. The red circles denote the share of individual torque values divided into road portions: urban, rural and motorway and their position indicates average values. This indicates the most frequent use of the torque value from the lower range of available torque values. It was observed that during the tests, the torque did not significantly exceed $150 \mathrm{Nm}$.

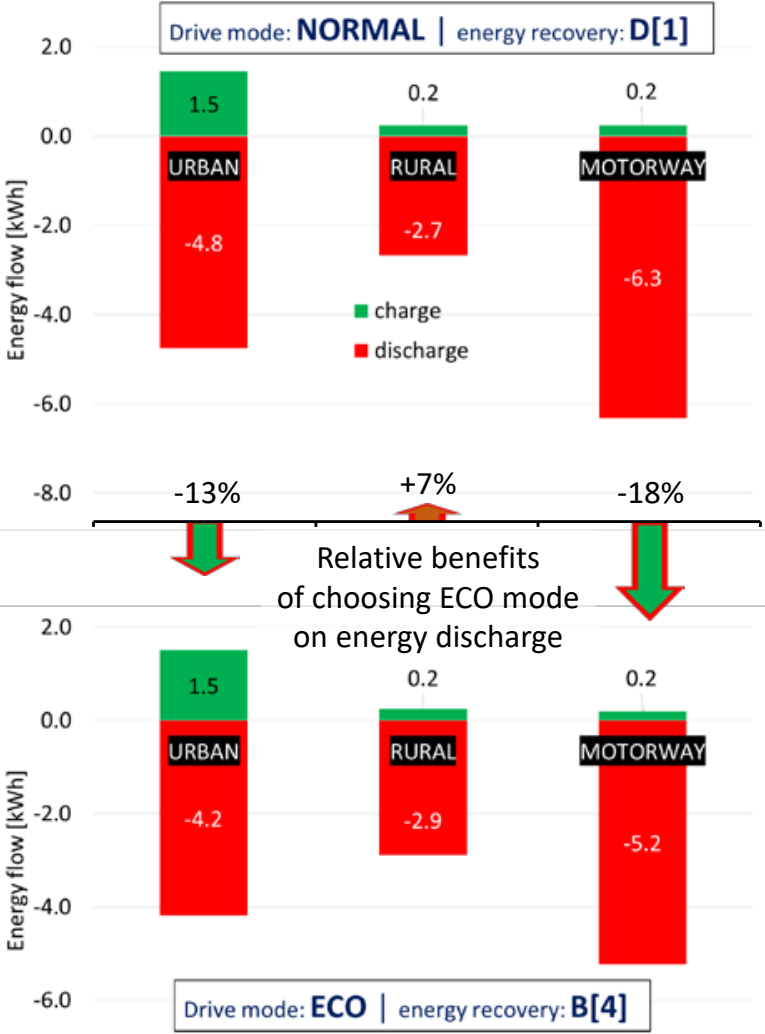

Fig. 18. Energy consumption balance in terms of different road types for Normal and ECO modes

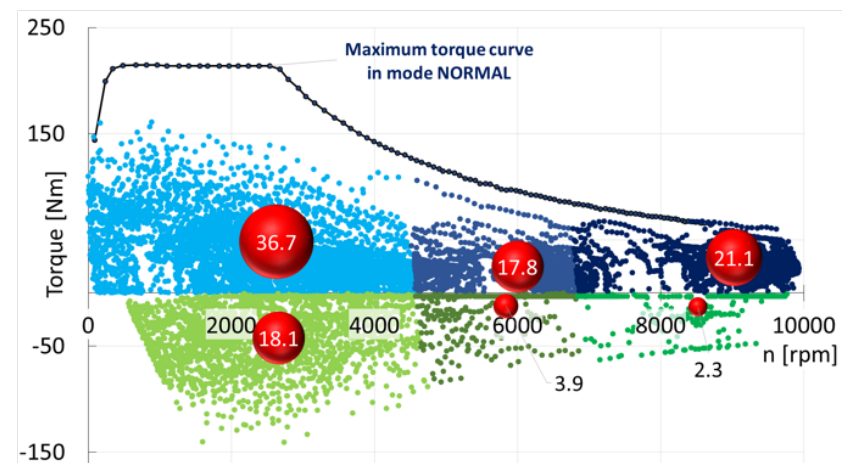

Drive mode: NORMAL | energy recovery: $\mathbf{D}[\mathbf{1}]$

$-250$

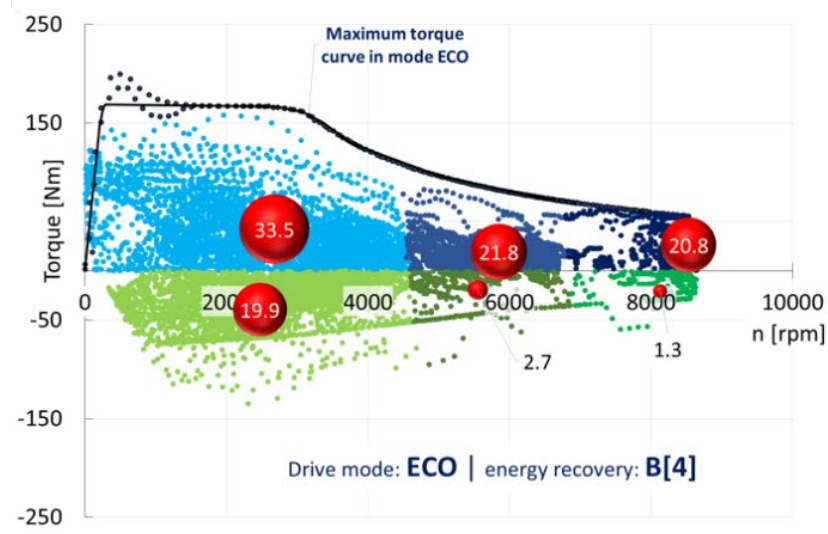

Fig. 19. The obtained torque distribution on the full load characteristic for NORMAL and ECO modes 
After activation of the $\mathrm{B}$ mode responsible for the regenerative braking assistance, one could clearly see the restrictions of the system operation through a linear alignment of the points in the lower quadrant of the presented chart. The points outside the line indicate independent braking of the driver. When using the $\mathrm{B}$ mode, each release of the accelerator pedal activated energy recovery. This was particularly visible at high engine speeds. The obtained values of the braking moment were, however, much lower in the ECO mode than in the NORMAL mode when the driver applied the brake.

\section{Conclusions}

This paper presented an analysis of the influence of the energy management and change of the regenerative braking strategy on the energy consumption and behavior of a passenger BEV vehicle. The results were obtained following road tests compliant with the RDC regime. All the test runs complied with these requirements.

During the first test run, the powertrain operated in the NORMAL mode with the active regenerative braking system assistance set to minimum. The second test run was carried out in the ECO mode activated manually by pressing the 'ECO' button. Additionally, the regenerative braking system assistance was set to the $\mathrm{B}$ mode. This means that the vehicle braked automatically when the gas pedal was released.

The following conclusions have been drawn:

1. When analyzing the SOC during the test, the greatest differences were observed in the motorway cycle. The ECO mode reduced the drop of the SOC by $5.3 \%$.

2. In the case of the ECO mode, the following were observed: a greater share of constant speed (by 3.3\%), acceleration (by 2.1\%) and deceleration (by 1.1\%) against the distance identical for both tests. These results were separate for each RDC test run and reflected the road congestion.

3. The flow of energy in the electric vehicle was realized in two directions - when accelerating the energy went to the electric motor and during regenerative braking it was recuperated to the battery. For both driving modes, the greatest amount of energy was recovered in the speed interval of $20-40 \mathrm{~km} / \mathrm{h}$. Greater values of instantaneous energy recovery were obtained in the NORMAL mode (driver braking). Also, greater instantaneous energy consumption in individual speed intervals in the NORMAL mode was observed.
4. Instantaneous energy consumption for the speeds in the $120-130 \mathrm{~km} / \mathrm{h}$ interval was $6.63 \mathrm{Wh}$ (in the NORMAL mode) and $4.9 \mathrm{Wh}$ in the $110-120 \mathrm{~km} / \mathrm{h}$ interval; the reduction of the speed by $10 \mathrm{~km} / \mathrm{h}$ resulted in a reduction of the instantaneous energy consumption by approx. $30 \%$.

5. The energy balance for the ECO mode indicates a lower energy consumption by $13 \%$ and $18 \%$ in the urban and expressway portions respectively. No differences in the energy recovery between the test runs were observed.

6. Activating the ECO mode restricts the vehicle power output. When driving, the most frequently applied torque falling in the lower range of the available interval was - 50 $\mathrm{N} \cdot \mathrm{m}$ (energy regeneration) to $50 \mathrm{~N} \cdot \mathrm{m}$ (driving) - Fig. 20.

7. Activating mode $\mathrm{B}$ did not influence the amount of recovered energy. It only changed the strategy of its regeneration. Despite the activation of mode B, in emergency situations it was necessary to use the main brake.

Summarizing, in the NORMAL mode the vehicles consumed $10.35 \%$ more energy than when it operated in the ECO mode. Irrespective of the applied mode, the amount of recovered energy was identical. The influence of regenerative braking rendered the best results in urban driving whether or not the regenerative braking assistance was activated.

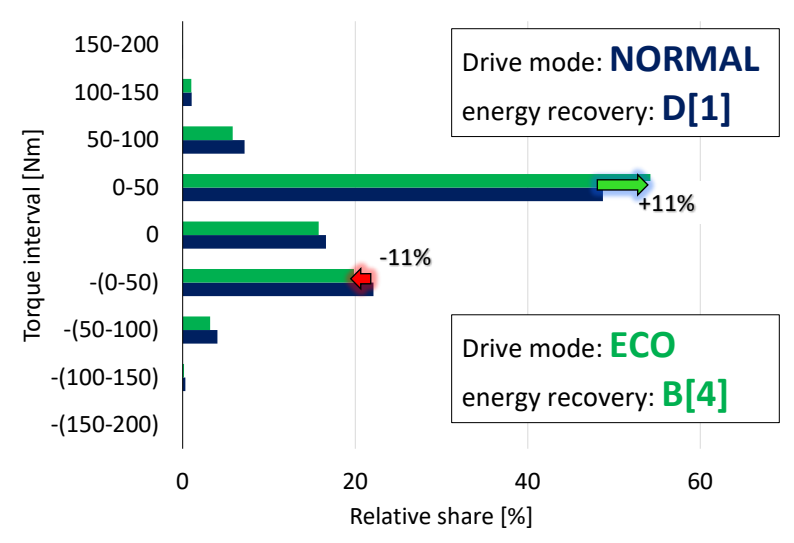

Fig. 20. Relative share of the torque interval during the RDC test for NORMAL and ECO modes

\section{Acknowledgements}

This work was supported by the Volkswagen Group Polska Sp. z o.o. and the Subvention of Polish Ministry of Higher Education, project number 0415/SBAD/0297 at Poznan University of Technology.

\section{Nomenclature}

$\begin{array}{ll}\text { BEV } & \text { battery electric vehicle } \\ \text { CAN } & \begin{array}{l}\text { controller area network } \\ \text { CE }\end{array} \\ \text { combustion engine } \\ \text { CI } & \text { compression ignition } \\ \text { CNG } & \text { compressed natural gas } \\ \text { DI } & \text { direct injection } \\ \text { EM } & \text { electric motor } \\ \text { EV } & \text { electric vehicle } \\ \text { FCEV } & \text { fuel cell electric vehicle } \\ \text { GHG } & \text { greenhouse gas }\end{array}$

ICE internal combustion engine

IVD in-vehicle display

LCA life cycle assessment

LPG liquified petrolum gas

MPI multi point injection

RDC real driving conditions

RDE real driving emission

SI spark ignition

SOC state of charge 


\section{Bibliography}

[1] BADIN, F., LE BERR, F., BRIKI, H. et al. Evaluation of EVs energy consumption influencing factors, driving conditions, auxiliaries use, driver's aggressiveness. 2013 World Electric Vehicle Symposium and Exhibition (EVS27). Barcelona 2013, 1-12.

https://doi.org/10.1109/EVS.2013.6914723

[2] BENVENISTE, G., RALLO, H., CANALS CASALS, L., et al. Comparison of the state of lithium-sulphur and lithiumion batteries applied to electromobility. Journal of Environmental Management. 2018, 226, 1-12.

https://doi.org/10.1016/j.jenvman.2018.08.008

[3] BRACO, E., MARTIN, I.S., BERRUETA, A. et al. Experimental assessment of cycling ageing of lithium-ion secondlife batteries from electric vehicles. Journal of Energy Storage. 2020, 32, 101695.

https://doi.org/10.1016/j.est.2020.101695

[4] BURCHART-KOROL, D., JURSOVA, S., FOLĘGA, P. et al. Life cycle impact assessment of electric vehicle battery charging in European Union countries. Journal of Cleaner Production. 2020, 257, 120476.

https://doi.org/10.1016/j.jclepro.2020.120476

[5] CABUKOGLU, E., GEORGES, G., KUNG, L. et al. Battery electric propulsion: an option for heavy-duty vehicles? Results from a Swiss case-study. Transportation Research Part C: Emerging Technologies. 2018, 88, 107-123.

https://doi.org/10.1016/j.trc.2018.01.013

[6] CASALS, L.C., GARCÍA, B.A., AGUESSE, F. et al. Second life of electric vehicle batteries: relation between materials degradation and environmental impact. International Journal of Life Cycle Assessment. 22, 82-93, 2017. https://doi.org/10.1007/s11367-015-0918-3

[7] CHANG-HEUM, J., SEUNG-TAEK, M. Efficient recycling of valuable resources from discarded lithium-ion batteries. Journal of Power Sources. 2019, 426, 259-265.

https://doi.org/10.1016/j.jpowsour.2019.04.048

[8] CHRISTOPHERSEN, J.P. Battery test manual for electric vehicles. Revision 3. United States: 2015.

https://doi.org/10.2172/1186745

[9] CIEŚLIK, W., PIELECHA, I., SZAŁEK, A. Assessment of parameters of the hybrid drive system in vehicles in urban traffic conditions. Combustion Engines. 2015, 161(2), 14-27.

[10] Commission Regulation (UE) 2019/631 of 17 April 2019.

[11] Electric Transport Revolution.

https://www.pveurope.eu/News/E-Mobility/Electric-

Transport-Revolution-Set-To-Spread-Rapidly-Into-Lightand-Medium-Commercial-Vehicle-Market

[12] YAO, E., YANG, Z., SONG, Y. et al. Comparison of electric vehicle's energy consumption factors for different road types. Discrete Dynamics in Nature and Society. 2013, 2013, 1-7. https://doi.org/10.1155/2013/328757

[13] FERNANDEZ, R.A., CARABALLO, S.C., LOPEZ F.C. A probabilistic approach for determining the influence of urban traffic management policies on energy consumption and greenhouse gas emissions from a battery electric vehicle. Journal of Cleaner Production. 2019, 236, 117604. https://doi.org/10.1016/j.jclepro.2019.117604

[14] FLUDER, K., PIELECHA, I., CIEŚLIK, W. The impact of drive mode of a hybrid drive system on the energy flow indicators in the RDE test. Combustion Engines. 2018, 175(4), 18-25. https://doi.org/10.19206/CE-2018-403

[15] FRIEDL, H., FRAIDL, G., KAPUS, P. Highest efficiency and ultra low emission - internal combustion engine 4.0. Combustion Engines. 2020, 180(1), 8-16. https://doi.org/10.19206/CE-2020-102
[16] GAO, Z., LACLAIR, T., OU, S. et al. Evaluation of electric vehicle component performance over eco-driving cycles. Energy. 2019, 172, 823-839. https://doi.org/10.1016/j.energy.2019.02.017

[17] GIS, W., MERKISZ, J. The development status of electric (BEV) and hydrogen (FCEV) passenger cars park in the world and new research possibilities of these cars in real traffic conditions. Combustion Engines. 2019, 178(3), 144149. https://doi.org/10.19206/CE-2019-325

[18] GIS, W., PIELECHA, J., MERKISZ, J. et al. Determining the route for the purpose light vehicles testing in Real Driving Emissions (RDE) test. Combustion Engines. 2019, 178(3), 61-66. https://doi.org/10.19206/CE-2019-311

[19] GIS, W., WAŚKIEWICZ, J., MENES, M. Experts forecasts on the demand for energy carriers in motor vehicle transport in Poland up to year 2035. Combustion Engines. 2019, 178(3), 162-165. https://doi.org/10.19206/CE-2019-328

[20] HE, L., YE, W., HE, Z. et al. A combining sliding mode control approach for electric motor anti-lock braking system of battery electric vehicle. Control Engineering Practice. 2020, 102, 104520. https://doi.org/10.1016/j.conengprac.2020.104520

[21] HELD, M., SCHUCKING, M. Utilization effects on battery electric vehicle life-cycle assessment: a case-driven analysis of two commercial mobility applications. Transportation Research Part D: Transport and Environment. 2019, 75, 87105. https://doi.org/10.1016/j.trd.2019.08.005

[22] How to use Real Driving Emission cycles in Simcenter Amesim? https://community.sw.siemens.com/s/article/howto-use-real-driving-emission-cycles-in-simcenter-amesim

[23] https://netcarshow.com/volkswagen/2014-e-up/

[24] https://elektrowoz.pl/auta/skoda-citigoe-iv-elektrycznaskoda-na-bazie-vw-e-up-już-oficjalnie/

[25] https://leasing.com/car-leasing-news/driven-skoda-fabia-se$1-0-75 /$

[26] https://www.statista.com/statistics/1081332/poland-numberof-registered-electric-passenger-cars/

[27] IEA, Global EV Outlook 2020, IEA, Paris https://www.iea.org/reports/global-ev-outlook-2020

[28] JEONGYONG, K., INHO, S., WOONGCHUL, C. An electric bus with a battery exchange system. Energies. 2015, 8, 6806-6819. https://doi.org/10.3390/en8076806

[29] KALT, S., BRENNER, L., LIENKAMP, M. Requirements for electric machine design based on operating points from real driving data in cities. World Electric Vehicle Journal. 2019, 10, 60. https://doi.org/10.3390/wevj10040060

[30] LI, L., LIU, Q. Study on the influence of acceleration curve on electric vehicle energy consumption and battery life. IOP Conference Series: Earth and Environmental Science. 2020, 512, 012106. https://doi.org/10.1088/1755-1315/512/1/012106

[31] LUK, J., KIM, H., DE KLEINE, R. et al. Impact of powertrain type on potential life cycle greenhouse gas emission reductions from a real world lightweight glider. SAE Technical Paper 2017-01-1274, 2017. https://doi.org/10.4271/2017-01-1274

[32] MCKERRACHER, C., IZADI-NAJAFABADI, A., O'DONOVAN, A. et al. Electric vehicle outlook 2020. https://about.bnef.com/electric-vehicle-outlook/

[33] MERKISZ, J., PIELECHA, J. Selected remarks about RDE test. Combustion Engines. 2016, 166(3), 54-61. https://doi.org/10.19206/CE-2016-340

[34] NAUMANEN, M., UUSITALO, T., HUTTUNEN-SAARIVIRTA, E. et al. Development strategies for heavy duty electric battery vehicles: comparison between China, EU, 
Japan and USA. Resources, Conservation \& Recycling. 2019, 151, 104413.

https://doi.org/10.1016/j.resconrec.2019.104413

[35] PIELECHA, I., CIEŚLIK, W., FLUDER, K. Analysis of energy management strategies for hybrid electric vehicles in urban driving conditions. Combustion Engines. 2018, 173(2), 14-18. https://doi.org/10.19206/CE-2018-203

[36] RALLO, H., BENVENISTE, G., GESTOSO, I. et al. Economic analysis of the disassembling activities to the reuse of electric vehicles Li-Ion batteries. Resources, Conservation and Recycling. 2020, 159, 104785.

https://doi.org/10.1016/j.resconrec.2020.104785

[37] SKEETE, J., WELLS, P., DONG, X. et al. Beyond the EVent horizon: battery waste, recycling, and sustainability in the United Kingdom electric vehicle transition. Energy Research \& Social Science. 2020, 69, 101581.

https://doi.org/10.1016/j.erss.2020.101581

[38] SUN, Z., WEN, Z., XIN, Z. et al. Real-world driving cycles adaptability of electric vehicles. World Electric Vehicle Journal. 2020, 11(1), 1-22.

https://doi.org/10.3390/WEVJ11010019

Wojciech Cieślik, DEng. - Faculty of Civil and Transport Engineering, Poznan University of Technology.

e-mail:wojciech.cieslik@put.poznan.pl
[39] Training data from Volkswagen group Poland company.

[40] WANG, G., MAKIN, K., HARMANDAYAN, A. et al. Ecodriving behaviors of electric vehicle users: a survey study. Transportation Research Part D: Transport and Environment. 2020, 78, 102188.

https://doi.org/10.1016/j.trd.2019.11.017

[41] WANG, J., BESSELINK, I., NIJMEIJER, H. Battery electric vehicle energy consumption prediction for a trip based on route information. Proceedings of the Institution of $\mathrm{Me}$ chanical Engineers, Part D: Journal of Automobile Engineering. 2018, 232(11), 1528-1542.

https://doi.org/10.1177/0954407017729938

[42] ZHAO, Y., YUAN, Z., JIANG, L. Regeneration and reutilization of cathode materials from spent lithium-ion batteries. Chemical Engineering Journal. 2020, 383, 123089. https://doi.org/10.1016/j.cej.2019.123089

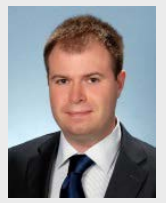

Filip Szwajca, MEng. - Faculty of Civil and Transport Engineering, Poznan University of Technology.

e-mail: filip.szwajca@put.poznan.pl

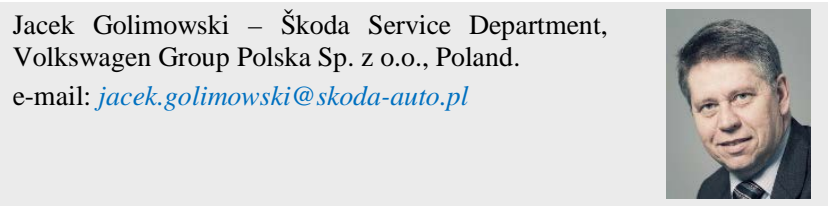

